\title{
Educação ambiental no processo de territorialização em saúde: apresentação de um método utilizado
}

\author{
Environmental education in the process of territorialization in health: \\ presentation of a method used
}

Sarah Leite Gomes', Alessandra Buonavoglia Costa-Pinto', Paula Peixoto Messias Barreto1

DOI: 10.1590/0103-11042019S518

RESUMO O objetivo deste artigo foi apresentar um método qualitativo de abordagem da educação ambiental no processo de territorialização em saúde. O percurso metodológico que dá origem a este texto é uma pesquisa-ação cujo estudo é do tipo exploratório e descritivo de abordagem qualitativa por meio do desenvolvimento de oficinas. Foram realizados seis encontros para atender aos objetivos propostos. As atividades foram desenvolvidas por um moderador e contaram com a participação de 60 Agentes Comunitários de Saúde atuantes em um município de pequeno porte do interior e do litoral da Bahia. Os resultados apontam que, no processo de territorialização em saúde, é elementar a incorporação de novas práticas que demonstrem o território além de demarcações geográficas, valorizando a concepção ampliada de ambiente e suas relações com a saúde. Nesse ponto, surge como proposta a reorganização dos processos de trabalho, no sentido de buscar multidisciplinaridade, interdisciplinaridade e participação efetiva no processo de territorialização em saúde à luz da educação ambiental.

PALAVRAS-CHAVE Métodos. Educação em ambiental. Saúde ambiental. Território em saúde.

\begin{abstract}
This paper aims to present a method of qualitative approach to environmental education in the process of territorialization in health. The methodological path that gives rise to this text is an action-research whose study is exploratory and descriptive of qualitative approach through the development of workshops. Six meetings were held to meet the proposed objectives. The activities were developed by a moderator and were attended by 60 Community Health Workers working in a small municipality in both the countryside and the coast of Bahia. The results indicate that, in the process of territorialization in health, it is elementary to incorporate new practices that demonstrate the territory beyond geographical demarcations, valuing the broader conception of the environment and its relations with health. In that regard, the proposal that arises is the reorganization of work processes, in the sense of seeking multidisciplinarity, interdisciplinarity and effective participation in the process of territorialization in health, in light of environmental education.
\end{abstract}

KEYWORDS Methods. Environmental health education. Environmental health. Health territory. 


\section{Introdução}

A educação ambiental deve fomentar a proposição de questionamentos e ações fundadas na mobilização comunitária e para a busca solidária do enfretamento e resolução de problemas elencados após a análise situacional, estimulando uma reflexão crítica a respeito da realidade em questão, de forma a propiciar a construção de novos conhecimentos sobre os temas discutidos.

Para ser efetiva, ela deve ser trabalhada em interface com as diferentes áreas, de modo interdisciplinar e intersetorial, pautada na articulação em redes de conexões e para a mobilização da cidadania em defesa da construção de uma consciência ambiental que se entrelaça rizomaticamente aos processos da sociedade, no meio público e privado, coletivo e individual, gerando mudanças profundas nos modos de ver e se ver no território.

Para Silva', a educação ambiental apresenta definições conservadora, pragmática e crítica, em que a primeira é centrada no indivíduo e tem como característica principal a proteção da natureza de forma intocada, sem interação com o ser humano. A pragmática busca solução para os problemas ambientais de forma focada e norteada por normas a serem seguidas; e a educação ambiental crítica questiona o modelo econômico vigente e propõe uma leitura complexa e dinâmica da relação homem-natureza fortalecendo a sociedade na busca coletiva de transformações sociais, apoiando-se na prática em que o pensamento crítico e a práxis norteiam as ações em função dos problemas apresentados.

A vertente crítica fomenta ações sobre a realidade dos problemas socioambientais com a finalidade de proporcionar um processo educativo no qual todos possam contribuir para as transformações desejadas na realidade, uma vez que os aspectos cognitivos e afetivos são primordiais para impulsionar os atores sociais na mudança de suas práticas interativas. Dessa forma, mostra-se como a corrente mais adequada para fazer frente a processos complexos uma vez que se propõe a despir a realidade, de maneira a contribuir para o processo de transformação social ${ }^{2}$, sendo esta a vertente que se alinha à política pública nacional.

No campo da saúde, a territorialização é um dos modos de lidar com o ambiente, o espaço e o território. A territorialização é um dos pressupostos basais do trabalho na Atenção Primária à Saúde (APS). Trata-se de uma ferramenta, uma metodologia primordial para o planejamento das ações de saúde que possibilita a identificação de aspectos ambientais, sociais, demográficos, econômicos, e dos principais problemas de saúde presentes no território ${ }^{3}$. É um processo que exige um olhar atento na busca pelo diagnóstico das vulnerabilidades e problemas identificados, com vistas ao seu oportuno enfrentamento 4 .

O território é o alicerce em que as determinações sociais da saúde produzem efeitos que o modificam. Os principais problemas desse território se dão nas relações entre saúde e ambiente, sendo necessário transformar as vulnerabilidades socioambientais em territórios sustentáveis e habitados por cidadãos e cidadãs saudáveis. As vulnerabilidades da relação entre o meio ambiente e a saúde se dão em decorrência dos processos e modelos de desenvolvimento ${ }^{5}$.

A territorialização é uma diretriz da APS que se baseia em uma forma de reconhecimento do território, primeiro nível de atenção à saúde. Inclui-se a maneira como se faz o diagnóstico do território, incluindo todas as técnicas utilizadas para tanto. O diagnóstico leva em conta as condições de saúde e de vida da população da área estudada. Assim, considera o acesso desses atores sociais aos serviços de saúde e viabiliza a execução de atividades específicas a realidade encontrada ${ }^{6}$.

Para Starfield 7 , a atenção primária e a saúde possuem muitos determinantes, um deles é o ambiente físico e social. De modo que, para avaliar saúde, é necessário envolver também fatores antecedentes como o contexto ambiental, devendo ainda ponderar as relações e condições sociais em situação.

No campo da saúde, o território vem sendo 
alvo de crescentes discussões que envolvem uma série de problemas relacionados com a compreensão do mesmo, já que a saúde deve ser promovida estabelecendo vínculo entre os serviços de saúde e a população. O fundamento é embasado para que haja a compreensão das necessidades e problemas de saúde do território, visto que, compreender território, permite descentralizar o modelo de atenção, não focando apenas na doença, e, sim, no espaço e sua relação com as situações econômicas, sociais e situação de saúde.

Os Agentes Comunitários de Saúde (ACS) são atores sociais dotados de potencialidades para o desenvolvimento de ações implicadas com o processo de implementação transversal da educação ambiental no cotidiano, destacando-se aí as relações entre saúde, ambiente e bem-estar social ${ }^{8}$. De modo que Camponogara, Erthal e Viero', ao conhecer o que pensam os ACS acerca da problemática ambiental, destacam que eles acreditam na íntima relação entre saúde e meio ambiente, bem como vislumbram sua responsabilidade de atuação ante a questão ambiental, especialmente, por meio da promoção da saúde.

Situação essa que evidencia a necessidade de que a educação ambiental seja abordada nos contextos de educação permanente desses trabalhadores da saúde, com vistas a fortalecer suas competências para a promoção da saúde, com base em pressupostos que valorizem a interface entre saúde e meio ambiente, que podem ainda culminar na potencialização de indivíduos e comunidade para o enfrentamento dos determinantes socioambientais e na prevenção dos agravos decorrentes da exposição humana a problemas ambientais?.

Observando o disposto, o presente estudo foi realizado com vistas à inclusão da temática da educação ambiental no processo de educação permanente dos ACS, bem como no processo de territorialização em saúde realizados por eles. Partindo-se do pressuposto de que a metodologia é algo imprescindível à pesquisa e ao processo organizacional, o objetivo geral deste artigo é apresentar um método qualitativo de abordagem da educação ambiental no processo de territorialização em saúde.

Acredita-se que o estudo apresentado seja necessário, inovador e capaz de contribuir para o processo de incorporação de novas metodologias e estratégias interdisciplinares, de baixo custo e amplo alcance de resultados no que tange ao processo de associação de conceitos provenientes do campo da educação ambiental enquanto parte constituinte do processo de territorialização em saúde.

\section{Material e métodos}

Trata-se de um estudo do tipo exploratório e descritivo ${ }^{10}$, de abordagem qualitativa", do tipo pesquisa-ação, denominada toda reflexão sobre a ação ${ }^{12}$, uma metodologia originada nas Ciências Sociais, a qual deve ser pensada como ideia dirigente, e não como sinônimo de modelos e normas a serem seguidos, de maneira que seu objeto é basicamente qualitativo $^{13}$. É uma metodologia de pesquisa na qual os participantes do processo investigativo são mobilizados a movimentarem-se sobre a temática pesquisada por meio de ações coletivas na busca por soluções aos problemas enfrrentados, exigindo ainda uma interação entre os participantes do estudo e os pesquisadores, que devem esclarecer os temas de forma acolhedora ${ }^{\mathbf{1 4}}$.

O estudo foi desenvolvido no contexto do Programa de Pós-Graduação em Ciências e Tecnologias Ambientais (PPGCTA), da Universidade Federal do Sul da Bahia (UFSB), Campus Sosígenes Costa (CSC) e vinculado ao Núcleo de Pesquisa e Extensão em Educação Ambiental (NUPEEA), da UFSB/Porto Seguro. O campo do estudo foi um município de pequeno porte do interior e do litoral extremo sul da Bahia, e o cenário do estudo foi a APS. Os participantes foram 60 ACS que desenvolviam suas atividades laborais no território durante o período da pesquisa.

A pesquisa descreve o método denominado 'Educação Ambiental no processo de 
Territorialização em Saúde', que tem como objetivo central incorporar a educação ambiental ao processo de territorialização em saúde. Para tanto, foi desenvolvido um processo Educador Ambientalista (EA crítica) por meio de um curso constituído por seis encontros no formato de oficinas mais ou menos bimestrais, ao longo do período de um ano, planejadas e conduzidas por um moderador e registradas por meio de fotografias digitais e um diário de campo.

Optou-se pela realização de oficinas pelo fato dessas permitirem discussão de temas pelos participantes, minimizando possíveis distorções de ideias e conceitos abordados, mas, principalmente, pelo fato de oficinas estimularem uma participação ativa dos envolvidos nas discussões, o que oportuniza a construção de conhecimento dos participantes a cerca dos assuntos abordados, coadunando-se assim, com a proposta da EA trazida nas políticas públicas brasileiras. Klausmeyer e Ramalho ${ }^{15}$ apontam a importância do desenvolvimento destas, em que os participantes devem ser totalmente envolvidos no processo.

Quanto ao moderador, trata-se de uma figura que exerce um papel importante na condução das atividades, com a finalidade de garantir organicidade à participação dos envolvidos, buscando com bom senso e sensibilidade, conduzir as ações com foco no interesse de estudo estimulando a participação dos interessados ${ }^{16}$. Deve, portanto, ter um papel bem definido, buscando contribuir nos momentos certos e oportunos, estruturando e conduzindo a atividade, motivando os participantes a fim de proporcionar a aproximação entre eles e, assim, compreender suas crenças e percepções ao decorrer das intervenções ${ }^{15}$, a fim de estimular nos mesmos um processo reflexivo a respeito das mesmas. $\mathrm{O}$ que, de acordo com a perspectiva freiriana de educação, é um caminho indispensável à construção de novos conhecimentos.

Nesse aspecto, cada uma do conjunto de seis oficinas do curso apresentou um objetivo específico definido que corrobora paulatinamente para o alcance do objetivo geral. Cada uma delas foi desenvolvida por meio de estratégias metodológicas majoritariamente participativas. Cada encontro apresentou uma denominação própria e abordou centralmente uma temática/conceito interligando a educação ambiental ao processo de territorialização em saúde.

Quanto aos aspectos éticos, observando a Resolução do Conselho Nacional de Saúde (CNS), no 466, de 12 de dezembro de 201217, a pesquisa foi aprovada pelo Comitê de Ética em Pesquisa da Universidade Federal do Sul da Bahia (CEP-UFSB), sob o Certificado de Apresentação para Apreciação Ética (CAAE) 03775118.6.0000.8467. Os participantes do estudo tiveram acesso ao Termo de Consentimento Livre e Esclarecido (TCLE) em duas vias.

A realização das oficinas foi iniciada tão somente após a emissão do parecer favorável pelo CEP-UFSB e a anuência da Secretaria de Saúde Municipal, de modo que a apresentação do projeto de pesquisa-ação ao gestor municipal mostrou-se um passo importante da pesquisa que permitiu o fortalecimento da ação e enfatizou sua importância junto ao grupo de participantes. A adesão dos ACS foi satisfatória e calorosa. As oficinas ocorreram conforme o calendário municipal (agenda dos ACS), a agenda do moderador e disponibilidade de espaço.

\section{Resultados e discussão}

\section{O método ‘Educação Ambiental no processo de Territorialização em Saúde'}

O método 'Educação Ambiental no processo de Territorialização em Saúde’ ilustrado na figura 1 contempla seis oficinas. A oficina 1, 'Território', teve o objetivo específico de apresentar o método que seria utilizado e os objetivos da formação, 
além de iniciar uma reflexão sobre o que é território e conceitos de vulnerabilidades a ele relacionadas. A oficina 2, 'Território em saúde e meio ambiente', teve o objetivo específico de aproximar os atores sociais dos conceitos de território em saúde e meio ambiente. A oficina 3, 'Processo trabalho do ACS e sua interface com o território em saúde e meio ambiente', apresentou o objetivo específico de fomentar a compreensão do processo de trabalho do ACS na identificação das principais vulnerabilidades/ situações-problema em saúde e meio ambiente presentes no território. A oficina 4, 'Território, vulnerabilidades em saúde e meio ambiente', estudou e discutiu casos contendo situações-problema e indicadores de vulnerabilidades em saúde e meio ambiente, tendo o objetivo específico de promover a consciência crítica dos ACS e dos atores sociais frente às adversidades relacionadas ao território, vulnerabilidades em saúde e meio ambiente. A oficina 5 , 'Vulnerabilidades em saúde e meio ambiente: conceituando problemas, elegendo causas e traçando estratégias de enfrentamento', teve o objetivo específico de avançar nos conceitos e na correlação teoria-prática (práxis). A oficina 6, 'Avaliação do método', teve o objetivo específico de avaliar o processo vivido ao longo da formação, cabendo, nesse caso, a avaliação quanto o método utilizado contribuiu para sua atuação profissional à aplicabilidade do método na realidade concreta.

Figura 1. Temáticas abordadas nas oficinas sobre educação ambiental no processo de territorialização em saúde

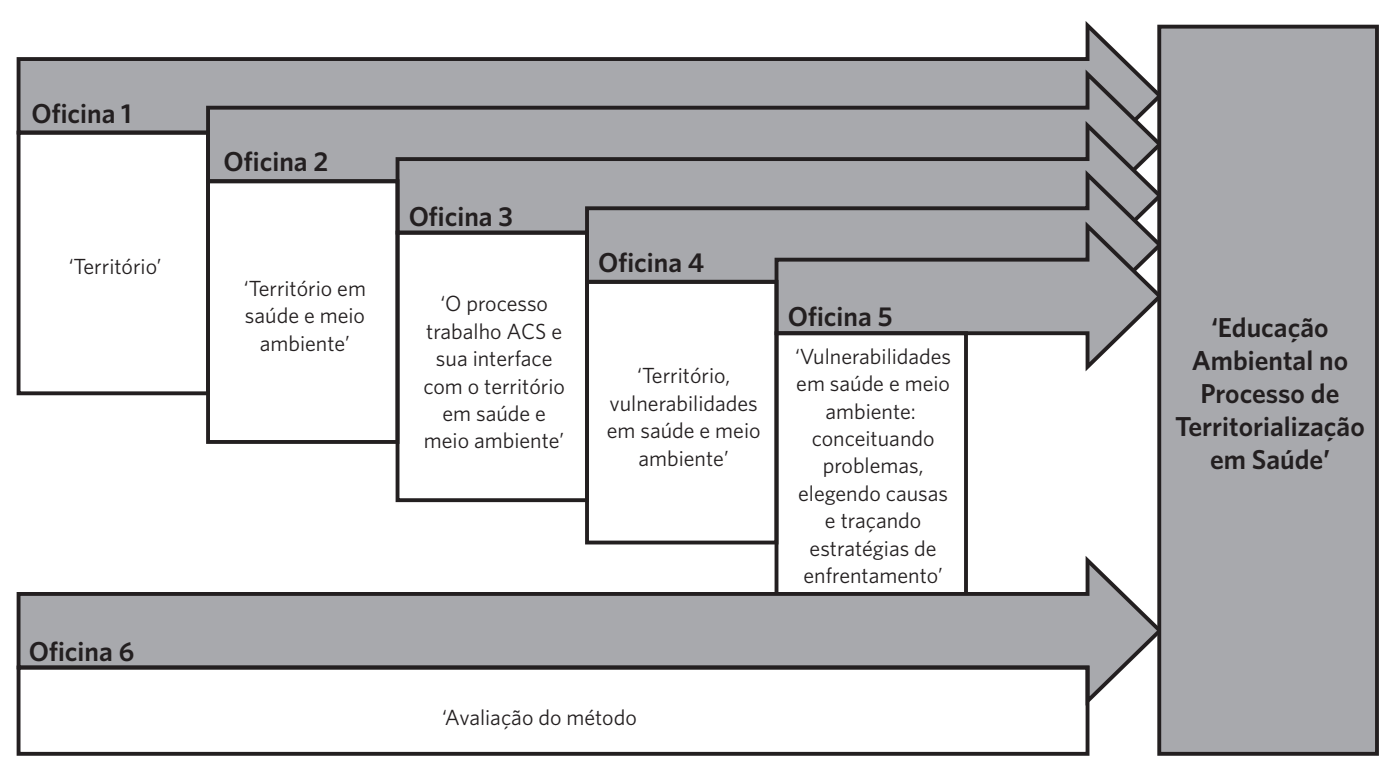

Fonte: Elaborado a partir do planejamento dos autores.

A periodicidade dos encontros foi estimada na medida do andamento das discussões, chegando ao intervalo de até dois meses entre uma oficina e outra. Cada oficina foi agendada antecipadamente, e os participantes foram convidados com certa antecedência. O local de realização foi preparado cuidadosamente de modo a comportar confortavelmente os participantes, dispondo de sanitários, sistema de ventilação e água para o livre consumo. 
Outro fator importante diz respeito à listagem, organização e obtenção prévia dos recursos didáticos e materiais necessários ao desenvolvimento das ações planejadas.

Assim, tem-se que o planejamento, a preparação prévia e o domínio das temáticas e estratégias metodológicas a serem trabalhadas foram de fundamental importância para o bom andamento do processo. Nesse contexto, fez-se necessário definir, com precisão qual seria a ação, quais seriam os agentes, quais os seus objetivos e desafios, bem como foi definida qual exigência de conhecimento a ser produzido em função dos problemas encontrados na ação ou entre os atores da situação ${ }^{18}$. Nesse contexto, os processos de comunicação se tornam de igual valor. Para Deslandes e Mitre ${ }^{19}$, a comunicação se constrói processualmente e envolve decisões existenciais em que a palavra e a práxis é central.

Tendo em vista que a fala é repleta de valores, e rica em experiências e facilitar a compreensão do intersubjetivo e social1", o curso valorizou as falas dos participantes e em todo encontro utilizou os mesmos critérios relativos à ordem e fala, de modo que, obedecendo aos princípios de ordem de inscrição, a fala foi permitida sempre aos presentes e principais pontos foram registrados em um diário de campo elaborado pelo moderador. Tem-se, então, que o processo formativo desenvolveu-se com a boa prática de comunicação.

A gestão do trabalho e o capital humano têm um desafio de curto prazo que é fazer frente à estratégia voltada para o apoio ao processo de aquisição de conhecimento, bem como de novas convenções ${ }^{20}$. A formação de Educação Ambiental em Saúde buscou ampliar a concepção de território dos ACS, bem como aprofundar a incorporação das condicionantes ambientais ao processo de APS.

Abaixo são apresentadas as análises do processo deflagrado junto aos ACS, de acordo com o propósito de cada uma das oficinas realizadas:

\section{Oficina 1: 'Território'}

\section{APRESENTAC̣ÃO DO MÉTODO, DOS OBJETIVOS E PACTUAÇÕES ENTRE MODERADOR E PARTICIPANTES}

Aproximações aos conceitos de território e vulnerabilidades relacionadas.

A primeira oficina do curso gira em torno da definição do conceito de território e vulnerabilidades relacionadas. No primeiro momento, realizou-se a apresentação da pesquisa, foi feito o convite à livre participação e a assinatura do TCLE em duas vias, ressaltando as questões éticas envolvidas. Em seguida, foram realizadas as pactuações entre moderadora e participante, para então proceder à apresentação do método a ser utilizado, seu objetivo, dos temas das oficinas propostas e seus objetivos específicos.

Com vistas à aproximação do grupo aos conceitos, a moderadora apresentou a proposta envolvendo os participantes no processo introdutório que chamou de 'definição de território', de modo que solicitou que eles se dividissem aleatoriamente em subgrupos para proceder à realização de uma dinâmica de grupo.

Guiados pela moderadora, os subgrupos constituídos passaram a compartilhar espaços delimitados com fita crepe no chão, sendo guiados a refletir sobre o espaço, conforto e características do território que conjuntamente ocupavam, o que permitiu a sensibilização do conceito de território enquanto bem comum. Em seguida, uma música foi introduzida à dinâmica e foi solicitado que os ACS passeassem livremente entre os diversos territórios delimitados no chão. Enquanto deambulavam, uma marcação de espaço foi retirada, sucedendo a dinâmica reducionista até restarem pequenos grupos com ocupação máxima do espaço delimitado.

Nesse momento, questionamentos sobre critérios de escolha ocupacional foram realizados pela moderadora, que evidenciou nos subgrupos de participantes a presença de idosos e gestantes presentes, que não foram 
priorizados pelos seus pares quanto em função de suas necessidades especiais na dinâmica de ocupação do território. Assim, reflexões foram realizadas fundadas em Hardin ${ }^{21}$ que aponta a relação do homem com o bem comum. Também foram realizadas reflexões em torno das vulnerabilidades identificadas.

Em seguida, textos abordando a temática do território foram distribuídos para enriquecer e fundamentar a atividade. Para a leitura, recomendou-se o método paragrafado, no qual representantes de grupo fazem a leitura de um ou mais parágrafos, sendo permitida a fala aos que desejassem contribuir.

Partindo da ideia de Santos ${ }^{22}$, que assegura que o território deve ser visto como algo essencial para a vida de todos e que está em constante mudança, buscou-se o uso de metodologias que utilizam de representações para a definição de território por meio do registro de forma livre. Assim, foram distribuídos conjuntos de cartolina e hidrocor aos grupos compostos por ACS de diferentes áreas de abrangência, e sugestionado que representassem livremente sua concepção de território, elaborando um registro do conceito de território por eles estabelecido em uma cartolina para posterior apresentação em roda.

Em roda, foram relatadas as experiências vivenciadas por intermédio da dinâmica de grupo quando puderam experimentar as sensações de compartilhar espaços, aproximar-se dos conceitos trabalhados e viabilizar a análise comportamental do grupo durante a execução da atividade. Também foram apresentadas as representações dos conceitos de território elaborados pelos grupos. Nesse aspecto, observa-se que as apresentações de produções visuais foram percebidas como fator motivacional aos participantes. Para Klausmeyer e Ramalho' ${ }^{15}$, a motivação de um grupo de trabalho passa pela criação de um centro de atenção comum, aqui podendo ser imagens reproduzidas ou criadas em cartazes, além da experiência vivenciada na dinâmica de ocupação de territórios. Essa técnica foi geradora de discussão do tema com menor dispersão e maior aproveitamento aos participantes.

\section{Oficina 2: 'Território em saúde e meio ambiente'}

\section{APROXIMAÇÕES AOS CONCEITOS DE TERRITÓRIO EM SAÚDE E MEIO AMBIENTE}

Ilustração do território sob responsabilidade sanitária dos ACS apontando as principais vulnerabilidades/situações-problema em saúde e meio ambiente.

A segunda teve o objetivo específico de aproximar os atores sociais dos conceitos de território em saúde e meio ambiente.

Cabe destacar que, assim como em todas as oficinas subsequentes, essa etapa do trabalho foi iniciada com o resgate da memória dos temas já abordados anteriormente como forma de sensibilização para a nova temática. Por conseguinte, procedeu-se à divisão dos participantes em subgrupos a fim de que realizassem as discussões em torno do território sob sua responsabilidade sanitária, apontando as principais vulnerabilidades e situações-problema em saúde e meio ambiente identificadas por eles.

Após a discussão, os subgrupos confeccionaram desenhos e esquemas conceituais sobre as situações elencadas em seus territórios de atuação que se constituíram de processos criativos desenvolvidos por meio da criação de imagens por eles, um formato que enriquece as representações sociais. Para Oliveira, Oliveira e Lobato ${ }^{23}$, a Representação Social é um saber comum constituído das vivências cotidianas do sujeito. As representações sociais são uma noção do senso comum e é constituída em razão do cotidiano dos participantes. Elas representam um corpus organizado de conhecimentos e constituem-se como uma das atividades psíquicas, graças às quais, tornam-se inteligíveis à realidade física e social24.

A subjetividade expressa por aspectos afetivos e simbólicos tem importância relevante na 
compreensão de fenômenos. Diversas técnicas em diferentes combinações tendem a enriquecer as representações sociais ${ }^{\mathbf{2 3}}$. Desse modo, as construções dos subgrupos foram apresentadas em roda, possibilitando discussões que enriqueceram o processo e facilitaram a identificação de vulnerabilidades no território, de modo que o segundo encontro foi marcado pela definição coletiva de território fundada nos textos lidos sobre território em saúde.

\section{Oficina 3: 'O processo trabalho do ACS e sua interface com o território em saúde e meio ambiente'}

\section{COMPREENSÃO DO PROCESSO DE TRABALHO DO ACS NA IDENTIFICAÇÃO DAS PRINCIPAIS VULNERABILIDADES/SITUAÇÕES-PROBLEMA EM SAÚDE E MEIO AMBIENTE PRESENTES NO TERRITÓRIO}

O plano de trabalho da terceira oficina do curso girou em torno da compreensão do processo de trabalho dos ACS e da sua interface com o território em saúde e meio ambiente. Para tanto, objetivou especificamente promover a compreensão de cada participante do lugar que ocupa, no seu processo de trabalho, a identificação das principais vulnerabilidades/ situações-problema em saúde e meio ambiente presentes no território, levando-os a refletir sobre isso.

Nesse encontro, procederam-se leituras dos materiais utilizados para trabalho e buscou-se a compreensão dos impressos (fichas) utilizados pelos ACS no seu processo laboral, procurando traçar a relação desses com a área de abrangência sob a ótica da identificação das principais vulnerabilidades/situações-problema em saúde e meio ambiente presentes no território, sensibilizando os participantes quanto ao seu processo de trabalho e relação com o território sob sua responsabilidade sanitária e constante vigilância. A atividade contou com a contribuição do grande grupo que relatou suas realidades perante as diferentes situações relacionadas por área de abrangência.

Foram esclarecidas dúvidas advindas da interpretação de alguns participantes quanto aos impressos (fichas) necessários ao trabalho; e, sabendo da normativa que regulamenta a ação do ACS na identificação de situações-problemas, a atividade proposta buscou também aperfeiçoar ações ditas como 'simples', a exemplo do cadastramento de uma família, sensibilizando-os para a construção de uma visão mais holística de suas ações que vão além dos requisitos obrigatórios solicitados, ampliando o diálogo com as questões relacionadas com o território em saúde e meio ambiente.

Observou-se que a dinâmica de leitura e exemplificações de situações se mostrou adequada e facilitou o processo de promoção da compreensão do lugar que ocupa a identificação de vulnerabilidades em saúde e meio ambiente no processo de trabalho do ACS. Portanto, foi possível minimizar desencaminhamentos apresentados pelo grupo, melhor precisando a vigilância ambiental em saúde que prevê informações sobre as características específicas do ambiente que tem relação com o padrão de saúde, as situações de risco existentes, os efeitos indesejáveis à saúde e a exposição a agravos ${ }^{25}$.

\section{Oficina 4: 'Território, vulnerabilida- des em saúde e meio ambiente'}

\section{ESTUDO E DISCUSSÃO DE CASOS ABORDANDO SITUAÇÕES-PROBLEMA CONTENDO INDICADORES DE VULNERABILIDADES EM SAÚDE E MEIO AMBIENTE}

A educação ambiental, segundo a política pública da área nacional e internacional, procura a igualdade, a solidariedade e o respeito às diferenças por meio do formato democrático de atuação embasada em práticas dialógicas e participativas. Dessa forma, fundamenta o objetivo de criar 
novos, comportamentos e atitudes diante do consumo da sociedade, e, dessa maneira, incentiva à mudança de valores coletivos e individuais 25 .

Partindo dessa ideia, a quarta oficina do curso busca promover o despertar da consciência crítica dos atores sociais ante as adversidades relacionadas com o território, vulnerabilidades em saúde e meio ambiente. Para tanto, os participantes, guiados pela moderadora, realizam estudo e discussões de casos contendo situações-problema e indicadores de vulnerabilidades em saúde e meio ambiente. Desse modo, o momento promoveu ainda mais a sensibilização do compromisso dos atores sociais perante as adversidades em situação.

A apresentação de slides contendo imagens de condições vulneráveis referentes à saúde e meio ambiente, entre outros desastres nesse contexto, foi feita de modo a provocar reflexões quanto às situações de vulnerabilidade em saúde e meio ambiente com foco na participação da sociedade sobre eles. As situações abordam problemas que vão além da área de cobertura das equipes de saúde, mas que exercem impactos diretos nela e vice-versa. Um exemplo utilizado foi à questão do lixo doméstico e restos de construção (entulho), sob a perspectiva da produção e do descarte desses resíduos.

Foi enfatizada a importância dos $3 R$ s, trazendo reflexões sobrea necessidade da ordem de primeiro reduzir o consumo, depois reutilizar coisas e, por fim, reciclar materiais, para que possamos, enquanto sociedade, transformar a situação vivida, no que toca, por exemplo a questão dos resíduos sólidos. A ideia foi gerar reflexões que possibilitassem uma mudança de comportamento diante da identificação de situações dessa natureza, buscando estimular novos modos de lidar com tais questões, visando a melhoria na qualidade de vida da população no território, que é indissociável da qualidade ambiental do mesmo. Podemos, assim, falar de qualidade socioambiental do território.
Oficina 5: 'Vulnerabilidades em saúde e meio ambiente: conceituando problemas, elegendo causas e traçando estratégias de enfrentamento'

\section{CONSTRUC̣ÃO DE MAPAS CONCEITUAIS ABORDANDO VULNERABILIDADES/SITUAC̄̃̃ES- PROBLEMA EM SAÚDE E MEIO AMBIENTE PRESENTES NO TERRITÓRIO, SUAS POSSÍVEIS CAUSAS ELEGÍVEIS E AS ESTRATÉGIAS DE ENFRENTAMENTO/SOLUC̣ÃO}

A quinta oficina foi desenvolvida por meio do exercício prático dos participantes. Estes foram divididos em subgrupos, por área de atuação, para o levantamento de situações- problemas relacionadas à área de atuação dos ACS. Os subgrupos foram munidos de papel ofício e hidrocor para a construção de mapas conceituais a partir do levantamento proposto.

Após a diagnose em subgrupo, sugeriu-se o registro da(s) palavra(s) que define(m) a situação-problema da área de abrangência da equipe, seguido das prováveis causas e soluções estratégias de enfrentamento para os entraves elencados. As produções foram recolhidas pela moderadora, digitalizadas e apresentadas em slides por representantes de cada um dos subgrupos. Uma música sobre a temática auxiliou no encerramento do dia.

Com a atividade, os participantes avançaram nos conceitos e na correlação teoria-prática (práxis) ao construir os mapas conceituais abordando situações-problema identificadas a partir da realidade concreta na qual estão inseridos, levando em conta seu processo de trabalho e os recursos disponíveis em suas realidades. A reflexão em torno das situações-problemas levantadas, bem como das possíveis causas e soluções com a apresentação de resultados durante a oficina, consentiu uma fidelização à ideia original pensada. Ideia essa se coaduna com as colocações de Sorrentino ${ }^{26}$ quando aponta que a educação ambiental tem o papel estimular a promoção da autorrealização individual e comunitária por meio do 
desenvolvimento de um processo educativo que contribua para a preservação da biodiversidade, facilitando a autogestão econômica e política das sociedades, promovendo, assim, a melhoria do meio ambiente e qualidade de vida da população.

Um exemplo prático pode ser identificado na frase 'falta de iluminação' elencada como situação-problema em saúde e meio ambiente em um dos territórios de saúde do grupo de ACS. A princípio, essa situação-problema poderia não ser apreciada como relevante, já que não apresentava coesão inicial com a temática proposta. No entanto, a apresentação do mapa conceitual desenvolvido pelo subgrupo evidenciou o significado posto à situação-problema 'falta de iluminação'.

Ao refletir sobre a situação-problema 'falta de iluminação', o subgrupo explicitou que ela pode ser um fator que impele os usuários da unidade de saúde, moradores do território em questão, buscar por meios ilícitos de acesso à eletricidade, comprometendo sua segurança. Um problema fomentado pela desigualdade social, resultado de uma relação desarmoniosa com o território e, portanto, de interesse para educação ambiental em saúde.

Um dos pilares do desequilíbrio socioambiental da atualidade é fomentado na crença da existência de uma relação desintegrada entre natureza e sociedade. Essa visão, surgida no período da modernidade, é também nutrida e disseminada pelos nos processos educativos formais (instituições de ensino em todos os níveis) e não formais, reforçando a ideia de que o ser humano não pode pensar junto a natureza e que deve dominá-la, ou ainda, que o ser humano não só não é parte da natureza, como também é superior aos outros seres vivos e não vivos. Esse comportamento é evidenciado socialmente na contemporaneidade como desigualdade social, desequilíbrio ecológico, intolerâncias diversas, individualismo, violência e solidão. A crise socioambiental advém dessa incapacidade de se relacionar com o outro e com o mundo ${ }^{2}$.

\section{Oficina 6: "Avaliando o método"}

\section{AVALIAC̣ÃO DO MÉTODO E DO SEU PROCESSO DE APLICABILIDADE}

A sexta oficina do curso teve o caráter avaliativo. Buscou levar os participantes à reflexão em torno dos temas trabalhados no processo e a avaliar o método utilizado (saber se a formação atingiu seu objetivo) e o processo de desenvolvimento e possível replicação dele na realidade concreta, considerando o cenário de atenção primária. A avaliação propriamente dita é realizada em roda e constadas reflexões doas participantes às questões norteadoras: 'Que bom'; 'Que pena'; 'Que tal?'.

Assim, para proceder à avaliação, a moderadora instruiu os participantes que, em resposta ao questionamento 'Que bom', as falas deveriam girar em torno dos pontos que julgaram positivos no curso; para a questão 'Que pena', as falas deveriam contemplar aspectos que não alcançaram as expectativas estimadas por eles durante a vivência; e, para a interrogativa 'Que tal?', as colocações deveriam atender ao quesito sugestões de melhoria e aperfeiçoamento do método.

Esse encontro foi extremamente gratificante e colaborativo para ambas as partes, moderadora e ACS. O que pode ser evidenciado por frases ditas pelos participantes durante o encerramento do ciclo de oficinas, extraídas do diário de campo elaborado pela moderadora:

\section{[...] tenho saído com uma visão de um mundo melhor onde eu posso fazer a diferença.}

\section{[...] o mundo avança muito rápido e precisamos} ter atenção a essas mudanças.

Percebi que posso reutilizar muita coisa que jogava fora.

Os ACS se mostraram comovidos com as condições de vida, saúde humana e ambiental do seu território de atuação profissional e foi 
expresso pelo grupo o(a) desejo/necessidade de continuação dos trabalhos voltados ao tema educação ambiental em saúde nos processos de educação permanente em saúde, por meio de processos educativos socioambientais críticos e continuados.

Observa-se que, embora tenha desenvolvido primeiramente junto aos ACS, o curso pode e deve ser ampliado a toda equipe de saúde. Situação que pode ser verificada recorrendo ao diário de campo, no qual há o registro de uma sugestão proposta pelos participantes, quando apontam a necessidade buscar a participação de equipe multidisciplinar no processo.

A partir disso, surge como proposta da moderadora e participantes a reorganização dos processos de trabalho no sentido de buscar multi e interprofissionalmente a resolução problemas na área da APS.

A situação traz à tona os conceitos de multidisciplinaridade, interdisciplinaridade e participação ampliada de atores sociais no processo de territorialização à luz da educação ambiental. Sabemos que a consciência crítica é fruto das correlações de circunstâncias e causas de experiências vividas ${ }^{27}$ e que mudanças costumam acontecer a partir da identificação de necessidades, que, por vezes, requisita inovações.

Aponta-se ainda como elementar a incorporação de novas práticas que tratem o território de maneira holística, para além de demarcações geográficas, valorizando a concepção ampliada de ambiente e suas relações com a saúde. Como aponta Carvalho ${ }^{28}$, a prática da educação ambiental crítica considera o ser humano situado historicamente tanto socialmente e individualmente; ela incide nas relações indivíduo-sociedade com a prática de responsabilidade com o ambiente, consigo próprio e com os outros.

Outro ponto identificado foi o desejo e a solicitação dos participantes de que haja encontros futuros a fim de mais encaminhamentos em torno da temática. O que leva à reflexão de que, embora programado para ocorrer em seis oficinas, o curso mostra-se aberto à inclusão de mais momentos a partir do diagnóstico situacional das localidades onde for implementado. Pode-se entender este processo composto por seis módulos como a primeira etapa de formação continuada em educação ambiental em saúde.

Cabe pontuar que lanches sustentáveis foram ofertados ao longo das realizações dos encontros como estímulos energéticos e reflexões de possibilidades. Os lanches oferecidos durante o curso possibilitaram a reflexão sobre o aproveitamento de alimentos, alinhando com economia, qualidade e sabor. Por exemplo, o suco de frutas, que foi servido em recipientes reutilizáveis, e algumas frutas, que tiveram suas cascas aproveitadas no preparo de chás. Trata-se de lanches mais acessíveis economicamente e que asseguram valor nutricional. $\mathrm{O}$ momento foi enriquecedor e promoveu diálogos informais acerca das formas de se alimentar, abordando o aspecto de responsabilidade pós-consumo, reflexão sobre o consumismo, ou mesmo o consumo consciente.

\section{Considerações finais}

O estudo apresentou um método qualitativo de abordagem da educação ambiental no processo de territorialização em saúde levando à conclusão de que, o processo de educação ambiental requer visão crítica sobre a realidade, prática social e relação com o meio ambiente. Colaborar para o planejamento de políticas de desenvolvimento urbano sustentável por meio de processos de educação ambiental é uma ação que se faz necessária em meio às ações do cotidiano.

A educação ambiental contribuiu com seus propósitos para o contexto da territorialização em saúde apresentando o potencial de impactar positivamente o processo de trabalho dos participantes da pesquisa. A metodologia dialógica utilizada, em consonância com a s propostas das políticas públicas de educação ambiental, oportunizou aos participantes a explanação de e a reflexão sobre suas próprias 
ideias, possibilitando assim a compreensão de conceitos e ideias do grupo em torno dos seus modos de se relacionar com o território. Tal prática mostrou-se capaz de permitir melhores diagnoses e, a partir disso, possibilitar a implementações de ações mais eficientes.

As oficinas constituíram-se de espaços oportunizadores de compartilhamento de saberes e de construção de novos conhecimentos capazes de ampliar a leitura de mundo dos sujeitos envolvidos, estando em diálogo com as proposições de Freire ${ }^{29}$ educar e educar-se é tarefa daqueles que sabem que pouco sabem e, por isso, sabem que sabem algo e que podem, assim, chegar a saber mais, em diálogo com aqueles que, frequentemente, pensam que nada sabem e ainda completa que os que pensam que nada sabem vão mudando o que sabem e todos saberão mais de alguma forma. Analisando qualitativamente chegou-se à conclusão de que os processos educacionais devem ser processuais, contínuos e articulados inter institucionalmente, de modo a envolver os diversos atores sociais e ampliar a equipe de multiplicadores que abordem a temática da educação ambiental no processo de territorialização em saúde, pois essa tendo sido uma das principais dificuldades encontradas.

Pelos resultados, embora preliminares, obtidos pela formação realizada compreende-se que o método dialógico utilizado foi bastante eficiente, pois atingiu os objetivos propostos, apontando na direção de uma visão mais holística dos ACS a respeito de seu território de atuação, de sua complexidade e de nuances importantes das inter-relações sociedade-natureza.

A partir das falas dos ACS é possível apontar uma mudança de comportamento que, talvez, seja capaz de colaborar como a minimização de impactos socioambientais locais em seus territórios de atuação e, consequentemente, com a promoção da saúde.

Os resultados obtidos reafirmam que a pesquisa-ação realiza um tipo de investigação que se utiliza de técnicas de pesquisa aplicadas na descrição dos efeitos de mudanças, viabilizando melhor compreensão do estudo; e causa, nos sujeitos envolvidos, transformações na forma de pensar e de se relacionar com o meio, o que, consequentemente, tem reflexo na melhoria da qualidade de vida das pessoas ${ }^{12}$.

\section{Colaboradores}

Gomes SL (0000-0001-7291-6112)*: contribuições substanciais para a concepção e delineamento do estudo; aquisição, análise ou interpretação dos dados do trabalho; elaboração de versões preliminares do artigo e revisão crítica de importante conteúdo intelectual; aprovação final da versão a ser publicada; concordância em ser responsável por todos os aspectos do trabalho, no sentido de garantir que as questões relacionadas à exatidão ou à integridade de qualquer parte da obra sejam devidamente investigadas e resolvidas. CostaPinto AB (0000-0002-5711-5453)* e Barreto PPM (0000-0002-2591-2853)*: análise e interpretação de dados do trabalho; revisão crítica de importante conteúdo intelectual; aprovação da versão final a ser publicada; concordância em ser responsável por todos os aspectos do trabalho, no sentido de garantir que as questões relacionadas à exatidão ou à integridade de qualquer parte da obra sejam devidamente investigadas e resolvidas. 


\section{Referências}

1. Silva RLF. O meio ambiente por trás da tela - estudo das concepções de educação ambiental dos filmes da TV escola [tese]. São Paulo: Universidade de São Paulo; 2007.

2. Guimarães M. Educação Ambiental Crítica. In: Layrargues PP, organizador. Identidades da Educação Ambiental Brasileira. Brasília, DF: Edições MMA; 2004. p. 25-34.

3. Araújo GB, Alves Filho FWP, Santos RS, et al. Territorialização em saúde como instrumento de formação para estudantes de medicina: relato de experiência.2017; Sanare. 16(1):124-129.

4. Pereira MPB, Barcellos C. O território no programa de saúde da família. Hygeia Uberlândia. 2006; 2(2):4755

5. Machado JMH, Martins JW, Souza MS, et al. Territórios saudáveis e sustentáveis: contribuição para saúde coletiva, desenvolvimento sustentável e governança territorial. Com Ciências Saúde. 2017; 28(2):243-249.

6. Colussi CF, Pereira KG. Territorialização como instrumento do planejamento local na atenção básica [recurso eletrônico]. Universidade Federal de Santa Catarina. Florianópolis: UFSC; 2016.

7. Starfield B. Atenção Primária: equilíbrio entre necessidades de saúde, serviços e tecnologia. Brasília, DF: Ministério da Saúde; 2002. 726 p. (Unesco).

8. Brasil. Ministério do Meio Ambiente. Educação Ambiental por um Brasil sustentável: ProNEA, marcos legais e normativos [recurso eletrônico]. Ministério do Meio Ambiente -MMA, Ministério da Educação - MEC. Brasília, DF: MMA, 2018.

9. Camponogara S, Erthal G, Viero CM. A Problemática Ambiental na visão de Agentes Comunitários de Saúde. Cienc Cuid Saude. 2013; 12(2):233-240.

10. Triviños ANS. Introdução à pesquisa em ciências sociais: a pesquisa qualitativa em educação. São Paulo: Atlas; 2009.
11. Minayo MCS. O desafio do conhecimento: pesquisa qualitativa em saúde. 12. ed. São Paulo: Hucitec; 2010.

12. Tripp D. Pesquisa-ação: uma introdução metodológica. Educação e pesquisa, São Paulo, v. 31, n. 3, p. 443466, set. 2005. Trimestral.

13. Deslandes SF, Cruz NO, Gomes R. Pesquisa Social: Teoria, método e criatividade. 3. ed. Petrópolis: Vozes; 1994. p. - 15.

14. Baldissera A. Pesquisa-ação: uma metodologia do "conhecer" e do "agir" coletivo. Sociedade em debate, Pelotas. 2001; 7(2):5-25.

15. Klausmeyer A, Ramalho L. Introdução a metodologias participativas: um guia prático. Recife: Sactes-ded; 1985.250 p.

16. Gondim SMG. Perfil profissional e mercado de trabalho: relação com formação acadêmica pela perspectiva de estudantes universitários. Estudo psicologia (Natal). 2002; 7(2):299-309.

17. Brasil. Resolução $n^{0} 466$ - diretrizes e normas regulamentadoras de pesquisas envolvendo seres humanos. Brasília, DF: Diário Oficial da União, 2012.

18. Thiollent M. Metodologia da pesquisa-ação. São Paulo: Cortez;1985.

19. Deslandes SF, Mitre RMA. Communicative process and humanization in healthcare. Interface - comunic Saude educ. 2009; 13(supl1):641-649.

20. Contandriopoulos AP, Champagne F. Elementos de arquitetura dos sistemas de avaliação de desempenho dos serviços de saúde. In: Contandriopoulos AP, Hartz Z, Gerhir M, organizadores. Saúde e cidadania: as experiências do Brasil e do Quebec. Campimnas: Saberes; 2010. p. 245-363.

21. Hardin G. The Tragedy of the Commons. Science. $1968 ; 162: 1243-1248$. 
22. Santos M. O território e o saber local: algumas categorias de análise. Cadernos IPPUR, Rio de Janeiro. 1999 ago; 2(13):15-23. Semestral.

23. Oliveira IA, Oliveira WMM, Lobato HKG. Pesquisa Educacional sobre representações sociais: o uso da técnica do desenho e dos mapas conceituais. São Carlos: Pedro \& João Editores; 2018. 89 p.

24. Moscovici S. A representação social da psicanálise. Rio de janeiro: Jorge Zahar; 1978.

25. Jacobi P. Educação ambiental, cidadania e sustentabilidade. Cadernos de pesquisa. São Paulo: autores associados. 2003; 118:189-205.

26. Sorrentino M. Educação ambiental e universidade: um estudo de caso [tese]. Faculdade de educação, São Paulo: Universidade de São Paulo, 1995.
27. Freire P. Educação e conscientização. In: Freire P. Educação como prática da liberdade. Rio de janeiro: Paz e terra; 1967. cap. 4. p. 101-121.

28. Carvalho ICM. Educação Ambiental crítica; nomes e endereçamentos da educação. In: Philippe Pomier Layrargues PP, coordoordenador. Identidades da educação ambiental brasileira. Brasília, SD: Ministério do Meio Ambiente. Diretoria de Educação Ambiental; 2004. 156 p.

29. Freire P. Educação e mudança. Rio de Janeiro. Paz e Terra, 1980.

Recebido em 22/05/2019

Aprovado em 31/10/2019

Conflito de interesses: inexistente

Suporte financeiro: não houve 